\title{
Efficacy and Safety of Ivabradine in Japanese Patients With Chronic Heart Failure - J-SHIFT Study -
}

Hiroyuki Tsutsui, MD, PhD; Shin-ichi Momomura, MD, PhD; Akira Yamashina, MD, PhD; Hiroaki Shimokawa, MD, PhD; Yasuki Kihara, MD, PhD; Yoshihiko Saito, MD, PhD;

Nobuhisa Hagiwara, MD, PhD; Hiroshi Ito, MD, PhD; Masafumi Yano, MD, PhD; Kazuhiro Yamamoto, MD, PhD; Junya Ako, MD, PhD; Takayuki Inomata, MD, PhD; Yasushi Sakata, MD, PhD; Takashi Tanaka; Yasushi Kawasaki on behalf of the J-SHIFT Study Investigators

\begin{abstract}
Background: Increased heart rate (HR) is an independent risk factor for cardiovascular outcomes in chronic heart failure (HF). Ivabradine, an If inhibitor, improved outcomes in patients with HF and reduced ejection fraction (HFrEF) in the SHIFT study. We evaluated its efficacy and safety in Japanese HFrEF patients in a randomized, double-blind, placebo-controlled phase III study: the J-SHIFT study. The main objective was to confirm a hazard ratio of $<1$ in the primary composite endpoint of cardiovascular death or hospital admission for worsening HF.
\end{abstract}

\begin{abstract}
Methods and Results: Patients with NYHA functional class II-IV, left ventricular EF $\leq 35 \%$, and resting HR $\geq 75$ beats/min in sinus rhythm under optimal medical therapy received ivabradine $(n=127)$ or placebo $(n=127)$. Mean reduction in resting HR was significantly greater in the ivabradine group (15.2 vs. 6.1 beats/min, $\mathrm{P}<0.0001)$. However, symptomatic bradycardia did not occur. A total of 26 $(20.5 \%)$ patients in the ivabradine group and $37(29.1 \%)$ patients in the placebo group had the primary endpoint event (hazard ratio $0.67,95 \% \mathrm{Cl} 0.40-1.11, \mathrm{P}=0.1179)$ during median follow-up of 589 days. Mild phosphenes were reported in $8(6.3 \%)$ patients in the ivabradine group and $4(3.1 \%)$ patients in the placebo group $(\mathrm{P}=0.3760)$.
\end{abstract}

Conclusions: The J-SHIFT study supported the efficacy and safety of ivabradine for Japanese HFrEF patients, in accord with the SHIFT study.

Key Words: Chronic heart failure; Heart rate; Ivabradine; Japanese; Left ventricular ejection fraction

A $n$ elevated resting heart rate $(\mathrm{HR})$ is reported to be an independent risk factor for death and cardiovascular outcomes in patients with heart failure (HF). ${ }^{1}$ Ivabradine is a pure HR-lowering agent that blocks the hyperpolarization-activated cyclic nucleotide-gated

\section{Editorial p 1991}

(HCN) channel responsible for the cardiac pacemaker If current in the sinoatrial node. ${ }^{2}$ The Systolic Heart failure

Received March 17, 2019; revised manuscript received June 10, 2019; accepted July 2, 2019; J-STAGE Advance Publication released online August 8,2019 Time for primary review: 19 days

Department of Cardiovascular Medicine, Graduate School of Medical Sciences, Kyushu University, Fukuoka (H.T.); Cardiovascular Division, Jichi Medical University, Saitama Medical Center, Saitama (S.M.); Department of Cardiology, Tokyo Medical University, Tokyo (A.Y.); Department of Cardiovascular Medicine, Tohoku University Graduate School of Medicine, Sendai (H.S.); Department of Cardiovascular Medicine, Hiroshima University Graduate School of Biomedical \& Health Sciences, Hiroshima (Y. Kihara); First Department of Internal Medicine, Nara Medical University, Kashihara (Y. Saito); Department of Cardiology, Tokyo Women's Medical University, Tokyo (N.H.); Department of Cardiovascular Medicine, Okayama University Graduate School of Medicine, Dentistry and Pharmaceutical Sciences, Okayama (H.I.); Division of Cardiology, Department of Medicine and Clinical Science, Yamaguchi University Graduate School of Medicine, Ube (M.Y.); Division of Cardiovascular Medicine, Endocrinology and Metabolism, Department of Molecular Medicine and Therapeutics, Faculty of Medicine, Tottori University, Yonago (K.Y.); Cardiovascular Medicine, Kitasato University, Sagamihara (J.A.); Cardiovascular Medicine, Kitasato University Kitasato Institute Hospital, Tokyo (T.I.); Department of Cardiovascular Medicine, Graduate School of Medicine, Osaka University, Suita (Y. Sakata); and Department of Clinical Development, Ono Pharmaceutical Co., Ltd., Osaka (T.T., Y. Kawasaki), Japan

Clinical Trial Registration: http://www.clinicaltrials.jp/user/cteSearch.jsp (JapicCTI-153007)

Mailing address: Hiroyuki Tsutsui, MD, PhD, Department of Cardiovascular Medicine, Graduate School of Medical Sciences, Kyushu University, 3-1-1 Maidashi, Higashi-ku, Fukuoka 812-8582, Japan. E-mail: htsutsui@cardiol.med.kyushu-u.ac.jp

ISSN-1346-9843 All rights are reserved to the Japanese Circulation Society. For permissions, please e-mail: cj@j-circ.or.jp 
treatment with the If inhibitor ivabradine Trial (SHIFT) showed the efficacy and safety of ivabradine in patients with $\mathrm{HF}$ and reduced ejection fraction (HFrEF). ${ }^{3} \mathrm{~A}$ phase II trial for Japanese patients with HFrEF demonstrated that ivabradine resulted in a significant reduction in resting HR compared with placebo, ${ }^{4}$ but the efficacy and safety of ivabradine remain unestablished in Japanese patients with HFrEF.

The Japanese SHIFT phase III study (J-SHIFT) was conducted to investigate the efficacy and safety of ivabradine on Japanese patients with HFrEF compared with placebo. Based on the results of the SHIFT study, thousands of patients are required to verify the statistically significant superiority of ivabradine to placebo for the mortality and morbidity endpoints. However, it was unrealistic to enroll this number of patients in a single-country trial in Japan. Therefore, the J-SHIFT study was designed to evaluate the consistency of results with those from the SHIFT study. Consistency was predefined as a point estimate of the hazard ratio $<1$ in the primary composite endpoint of cardiovascular death or hospital admission for worsening $\mathrm{HF}$. This concept is similar to that used in the J-EMPHASIS trial, a randomized double-blind placebo-controlled study, to determine the similar efficacy and safety of eplerenone in Japanese patients as in the EMPHASIS trial. ${ }^{5}$

\section{Methods}

\section{Study Design and Patients}

This was a multicenter, randomized, double-blind, placebocontrolled, parallel-group study in Japanese patients with HFrEF. The study consisted of 2 periods: a 2-week observation period followed by a treatment period of at least 52 weeks, during which patients received either ivabradine or placebo (Supplementary Figure 1). Patients were enrolled from 146 institutions in Japan between October 2015 and August 2018 (Supplementary Appendix).

Key inclusion and exclusion criteria are shown in Supplementary Table 1. Briefly, eligible patients were $\geq 20$ years of age, had stable symptomatic chronic HF of New York Heart Association (NYHA) functional class II-IV, left ventricular $\mathrm{EF}$ (LVEF) $\leq 35 \%$, resting $\mathrm{HR} \geq 75$ beats $/ \mathrm{min}$ in sinus rhythm, received optimal treatment for $\mathrm{HF}$ according to the Japanese Guidelines for Treatment of Chronic Heart Failure, ${ }^{6,7}$ and had a history of hospital admission for worsening HF within the preceding 52 weeks. Exclusion criteria included myocardial infarction within the previous 8 weeks, ventricular or atrioventricular pacing $>40 \%$ of $24 \mathrm{~h}$, persistent atrial fibrillation or flutter, and symptomatic hypotension. The inclusion and exclusion criteria for the J-SHIFT study were similar to those for the SHIFT study, except for the baseline resting HR $\geq 75$ beats/min in J-SHIFT compared with $\geq 70$ beats $/ \mathrm{min}$ in the SHIFT study. ${ }^{3}$ This modification was based on the posthoc subgroup analysis in the SHIFT study demonstrating consistent and statistically significant improvement in all clinical events, including all-cause and cardiovascular death, in patients with baseline resting HR $\geq 75$ beats $/ \mathrm{min}^{8}$ Changes in drug treatments for chronic HF were not allowed in the 4 weeks prior to the initiation of the observation period or during the treatment period, except for the occurrence of adverse events (AEs). Medications, including $\beta$-blockers other than carvedilol or bisoprolol fumarate, non-dihydropyridine calcium-channel blockers, class I antiarrhythmics, moderate or strong inhibitors of cytochrome P450 3A4, cytochrome P450 3A4 inducers, and any unapproved drugs were not permitted during the observation or treatment periods.

The study conformed to the principles outlined in the Declaration of Helsinki ${ }^{9}$ and Good Clinical Practice guidelines $^{\mathbf{1 0}}$ and was approved by the ethical committee or review board of each institution. All patients provided written informed consent before study enrollment.

\section{Randomization and Masking}

After the 2-week observation period to confirm the inclusion and exclusion criteria, patients were randomly allocated to either the ivabradine or placebo group at 1:1. A minimization method for dynamic allocation was used with adjustment for study site, baseline resting HR ( $\geq 85$ and $<85$ beats/min), and $\beta$-blocker dose before study treatment $(0,>0-<50$, and $\geq 50 \%$ of the target dose of carvedilol $20 \mathrm{mg} /$ day and bisoprolol $5 \mathrm{mg} /$ day) to balance baseline covariates. Patients and investigators were masked to treatment allocation, and study medications (ivabradine or placebo) were the same size and color.

\section{Study Procedures (Supplementary Figure 1)}

Ivabradine or placebo was started at $2.5 \mathrm{mg}$ twice daily (BID). The dose was adjusted at each visit in the range of 2.5-7.5 mg BID according to dose adjustment criteria; the dose was increased if the resting HR was higher than 60 beats $/ \mathrm{min}$, maintained if between 50 and 60 beats $/ \mathrm{min}$, decreased if lower than 50 beats/min or patients had signs or symptoms related to bradycardia, and discontinued if lower than 50 beats/min or the patient had signs or symptoms related to bradycardia at the lowest dose. All patients were treated with the study drug for a minimum 52 weeks and followed until the 52-week follow-up of the last enrolled patient.

At every visit during the treatment period, patients underwent a physical examination and an assessment of NYHA functional class, resting HR measured by 12-lead ECG, vital signs, B-type natriuretic peptide (BNP), N-terminal prohormone of BNP (NT-proBNP), and laboratory tests. LV end-diastolic volume (LVEDV), LV end-systolic volume (LVESV), and LVEF measured by echocardiography using the modified Simpson's method were measured at 2 months, and subsequently every 6 months. The occurrence of prespecified clinical events, including death or hospital admission for any cause, was recorded. AEs were recorded throughout the treatment period. When the study drug was discontinued because of AEs, prespecified clinical events were recorded until study completion.

\section{Study Endpoints}

The primary endpoint was the composite of cardiovascular death or hospital admission for worsening HF, as in the SHIFT study. ${ }^{3}$ The secondary endpoints were all-cause, cardiovascular, or HF death; hospital admission for all causes, cardiovascular causes, or worsening $\mathrm{HF}$, and a composite of cardiovascular death, hospital admission for worsening $\mathrm{HF}$, or hospital admission for non-fatal myocardial infarction. Changes in resting HR, NYHA functional class, LVEDV index, LVESV index, LVEF, BNP, and NT-proBNP were also assessed. Safety endpoints included AEs including vital signs, laboratory tests, and 12-lead ECG. An endpoint adjudication committee, independent from the sponsor and investigators, evaluated all clinical events according to prespecified definitions in a 


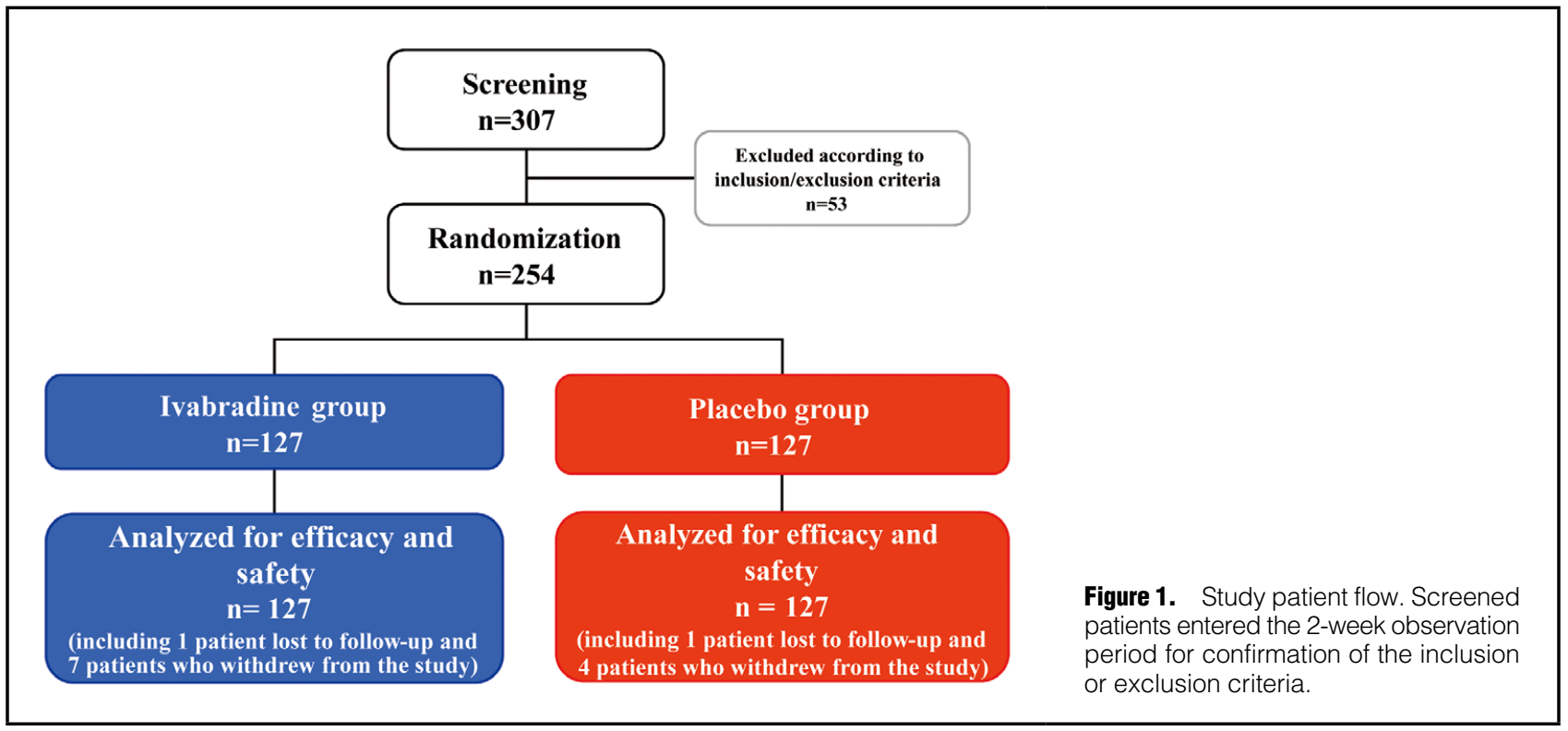

blinded manner. All HRs, BNP, and NT-proBNP were measured by central laboratories.

\section{Statistical Analysis}

The aim of the J-SHIFT study was to confirm numerical improvement in the primary composite endpoint of cardiovascular death or hospital admission for worsening $\mathrm{HF}$ as a point estimate of the hazard ratio $<1$ because of feasibility. SAS version 9.3 software (SAS Institute, Inc., Cary, NC, USA) was used for all statistical analyses. Patients' baseline characteristics, and categorical and continuous data were compared between groups using chi-square and t test, respectively. HR, LVEDV index, LVESV index, LVEF, BNP, NT-proBNP, systolic blood pressure (SBP), and diastolic blood pressure (DBP) were compared using analysis of covariance (ANCOVA). NYHA functional class was analyzed using chi-square test. The primary and secondary endpoints were analyzed using the Kaplan-Meier method (curves, median and 95\% confidence interval [CI]), Cox proportional hazards model (hazard ratios, two-sided 95\% CI) with treatment group as a factor, and resting HR and percentage of the target $\beta$-blocker dose at baseline as covariates. The consistency of the treatment effects was assessed among subgroups. The effect in each subgroup was analyzed using a Cox proportional hazard model with treatment group as a factor, and resting HR and percentage of the target $\beta$-blocker dose at baseline as covariates. P-values were calculated by adding the interaction term between the treatment groups and the subgroup status to the Cox model for primary composite endpoint. Incidence of AEs was analyzed using Fisher's exact test. All randomized patients were analyzed for efficacy. All study drug-treated patients after randomization were analyzed for safety.

The J-SHIFT study was designed to treat all the patients with the study drug for a minimum of 52 weeks and follow until 52 weeks from when the last patient was enrolled. This was aimed to collect as many clinical endpoints as possible. The sample size and the duration of follow-up were determined to ensure the statistical power to observe the positive trend (hazard ratio $<1$ ) in the primary composite endpoint, not to confirm statistical significance. The estimated number of patients required for the present study was 100 per group and assuming a $20 \%$ occurrence of study discontinuation or dropouts. The target patient number was calculated to be 125 patients per group.

\section{Results}

\section{Patients' Characteristics}

The study patient flow is shown in Figure 1: 307 patients were screened and entered the observation period; 53 patients were excluded according to the inclusion/exclusion criteria. Thus, 254 patients were enrolled and randomly assigned to the treatment groups: 127 patients in the ivabradine group and 127 patients in the placebo group. All patients enrolled into the study were analyzed for both efficacy and safety; $2(0.8 \%)$ patients were lost during follow-up and $11(4.3 \%)$ patients discontinued the study. These patients were censored at their last contact time.

The baseline characteristics were well balanced between the ivabradine and placebo groups (Table 1). The mean age was $60.6 \pm 13.5$ years, and $209(82.3 \%)$ patients were men. Mean resting HR was $82.4 \pm 7.7$ beats/min and LVEF was $27.2 \pm 5.7 \%$. The primary cause of HF was ischemic in $99(39.0 \%)$ and non-ischemic in $155(61.0 \%)$ patients. Most patients (202 [79.5\%] patients) were in NHYA functional class II and $52(20.5 \%)$ patients were in NHYA functional class III or IV. Angiotensin-converting enzyme (ACE) inhibitor and/or angiotensin receptor blocker (ARB) was used in $174(68.5 \%)$ patients, $\beta$-blocker in $242(95.3 \%)$ patients, mineralocorticoid receptor antagonist (MRA) in $197(77.6 \%)$ patients, diuretic in $230(90.6 \%)$ patients, and digitalis in $19(7.5 \%)$ patients. $\beta$-blocker was used in 127 $(50.0 \%)$ patients with at least $50 \%$ of the target dose defined by the guidelines, ${ }^{7}$ and in $49(19.3 \%)$ patients with the target dose. Predominant reasons for not receiving the target dose of $\beta$-blocker were hypotension $(59.6 \%)$, decompensated HF $(19.7 \%)$, dizziness $(9.8 \%)$, and fatigue $(8.8 \%)$. The reasons among 12 patients for not having $\beta$-blockers included bronchial asthma $(25.0 \%)$ and decompensated HF $(25.0 \%)$.

These baseline characteristics were also generally similar 


\begin{tabular}{|c|c|c|c|}
\hline & $\begin{array}{l}\text { Ivabradine group } \\
\qquad(n=127)\end{array}$ & $\begin{array}{l}\text { Placebo group } \\
\quad(n=127)\end{array}$ & P value* \\
\hline Age (years) & $61.2 \pm 13.3$ & $60.1 \pm 13.7$ & 0.5128 \\
\hline Sex (male) & $107(84.3)$ & $102(80.3)$ & 0.4113 \\
\hline BMI $\left(\mathrm{kg} / \mathrm{m}^{2}\right)$ & $24.6 \pm 4.9$ & $25.4 \pm 5.7$ & 0.2302 \\
\hline HR (beats/min) & $82.1 \pm 7.2$ & $82.7 \pm 8.1$ & 0.5531 \\
\hline $\mathrm{SBP}(\mathrm{mmHg})$ & $115.3 \pm 18.1$ & $116.4 \pm 18.5$ & 0.6344 \\
\hline $\mathrm{DBP}(\mathrm{mmHg})$ & $70.8 \pm 11.8$ & $71.6 \pm 12.5$ & 0.6000 \\
\hline LVEF (\%) & $27.9 \pm 5.3$ & $26.6 \pm 6.1$ & 0.0680 \\
\hline $\mathrm{BNP}(\mathrm{pg} / \mathrm{mL})$ & $334.5 \pm 400.0$ & $410.8 \pm 529.8$ & 0.1962 \\
\hline NT-proBNP (pg/mL) & $1,940.0 \pm 2,753.3$ & $1,920.7 \pm 2,198.3$ & 0.9506 \\
\hline eGFR $\left(\mathrm{mL} / \mathrm{min} / 1.73 \mathrm{~m}^{2}\right)$ & $65.3 \pm 26.3$ & $66.3 \pm 24.0$ & 0.7617 \\
\hline NYHA functional class & & & 0.9497 \\
\hline II & $100(78.7)$ & $102(80.3)$ & \\
\hline III & $25(19.7)$ & $23(18.1)$ & \\
\hline IV & $2(1.6)$ & $2(1.6)$ & \\
\hline Duration of HF (years) & $5.4 \pm 5.9$ & $4.3 \pm 5.0$ & 0.1422 \\
\hline Primary cause of HF & & & 0.8976 \\
\hline Ischemic & 49 (38.6) & $50(39.4)$ & \\
\hline Non-ischemic & $78(61.4)$ & $77(60.6)$ & \\
\hline \multicolumn{4}{|l|}{ Medical history } \\
\hline Hypertension & $52(40.9)$ & $57(44.9)$ & 0.6122 \\
\hline Diabetes mellitus & $67(52.8)$ & $56(44.1)$ & 0.2092 \\
\hline Dyslipidemia & $90(70.9)$ & $90(70.9)$ & 1.0000 \\
\hline $\mathrm{MI}$ & $27(21.3)$ & $39(30.7)$ & 0.1151 \\
\hline Angina pectoris & $27(21.3)$ & $31(24.4)$ & 0.6541 \\
\hline Atrial fibrillation/flutter & $12(9.4)$ & $11(8.7)$ & 1.0000 \\
\hline \multicolumn{4}{|l|}{ Medications } \\
\hline ACE inhibitor & $57(44.9)$ & $67(52.8)$ & 0.2585 \\
\hline ARB & $31(24.4)$ & $20(15.7)$ & 0.1167 \\
\hline ACE inhibitor and/or ARB & $88(69.3)$ & $86(67.7)$ & 0.8926 \\
\hline Diuretic (excluding MRA) & $114(89.8)$ & $116(91.3)$ & 0.8306 \\
\hline MRA & $106(83.5)$ & $91(71.7)$ & 0.0347 \\
\hline Digitalis & $10(7.9)$ & $9(7.1)$ & 1.0000 \\
\hline$\beta$-blocker & $122(96.1)$ & $120(94.5)$ & 0.7689 \\
\hline$\%$ of the target $\beta$-blocker dose ${ }^{\dagger}$ & & & 0.9660 \\
\hline 0 & $5(3.9)$ & $7(5.5)$ & \\
\hline$>0-<50$ & $58(45.7)$ & $57(44.9)$ & \\
\hline $50-<100$ & $39(30.7)$ & $39(30.7)$ & \\
\hline 100 & $25(19.7)$ & $24(18.9)$ & \\
\hline
\end{tabular}

Data are mean \pm SD or number of patients (\%). ${ }^{*}$ Chi-square test for categorical variables and analysis of variance for continuous variables. ${ }^{\dagger}$ Target $\beta$-blocker dose: carvedilol $20 \mathrm{mg} /$ day and bisoprolol $5 \mathrm{mg} /$ day. ACE, angiotensinconverting enzyme; ARB, angiotensin II receptor blocker; BMI, body mass index; BNP, brain natriuretic peptide; DBP, diastolic blood pressure; eGFR, estimated glomerular filtration rate; HF, heart failure; HR, heart rate; LVEF, left ventricular ejection fraction; MI, myocardial infarction; MRA, mineralocorticoid receptor antagonist; NT-proBNP, $\mathrm{N}$-terminal prohormone of brain natriuretic peptide; NYHA, New York Heart Association; SBP, systolic blood pressure.

to those in the SHIFT study, except for higher resting HR ( 82.4 vs. 79.9 beats $/ \mathrm{min}$ ), because of the difference in the inclusion criteria of resting HR ( $\geq 75$ in J-SHIFT vs. $\geq 70$ beats/min in the SHIFT study), higher prevalence of NYHA functional class II ( $79.5 \%$ vs. $48.7 \%)$, lower ischemic cause of HF (39.0\% vs. $67.9 \%)$, lower prevalence of hypertension $(42.9 \%$ vs. $66.3 \%)$, higher prevalence of diabetes mellitus $(48.4 \%$ vs. $30.4 \%)$, lower history of myocardial infarction $(26.0 \%$ vs. $56.4 \%)$, lower use of ACE inhibitor and/or ARB (68.5\% vs. $91.1 \%)$, higher use of MRA (77.6\% vs. $60.3 \%)$, and lower use of digitalis $(7.5 \%$ vs. $21.8 \%)$ (Supplementary Table 2). The percentage distribution of the target $\beta$-blocker dose was similar between the studies (Supplementary Table 2).

\section{Study Drug Administration and Follow-up}

There was no difference in treatment adherence, which was greater than $98 \%$ in each group. The median treatment duration was 561 and 549 days in the ivabradine and placebo groups, respectively $(\mathrm{P}=0.3247)$. The mean dose in the ivabradine group was $6.4 \pm 1.8 \mathrm{mg}$ BID at 6 weeks, $6.7 \pm 1.8 \mathrm{mg}$ BID at 56 weeks, and $6.2 \pm 2.3 \mathrm{mg}$ BID at the end of treatment. At the end of treatment in the ivabradine group, $90(70.9 \%)$ patients were on the highest dose of 
A

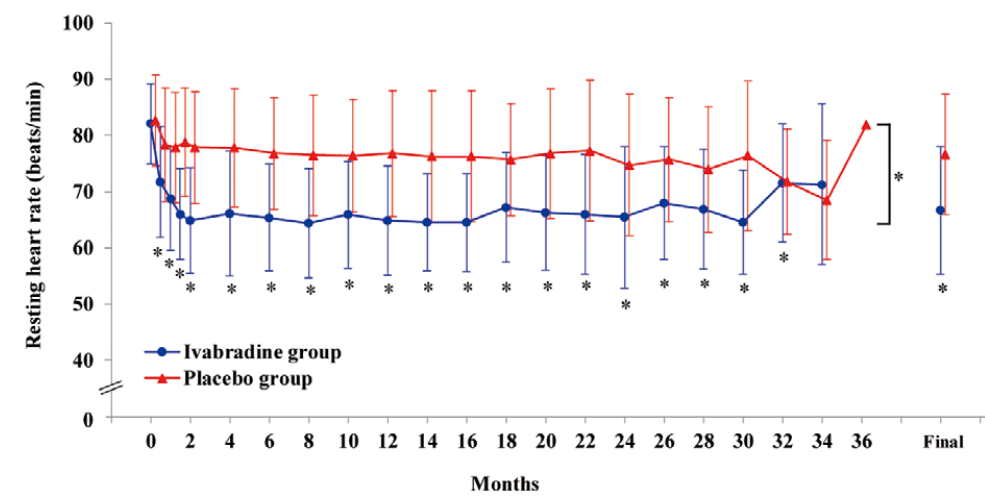

Number of patients

$\begin{array}{lllllllllllllllllllllll}\text { Ivabradine group } & 125 & 122 & 115 & 116 & 116 & 115 & 116 & 106 & 94 & 79 & 70 & 58 & 45 & 38 & 26 & 16 & 11 & 4 & 0 & 127\end{array}$

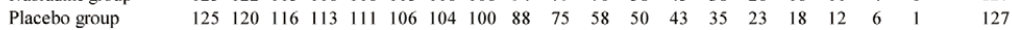
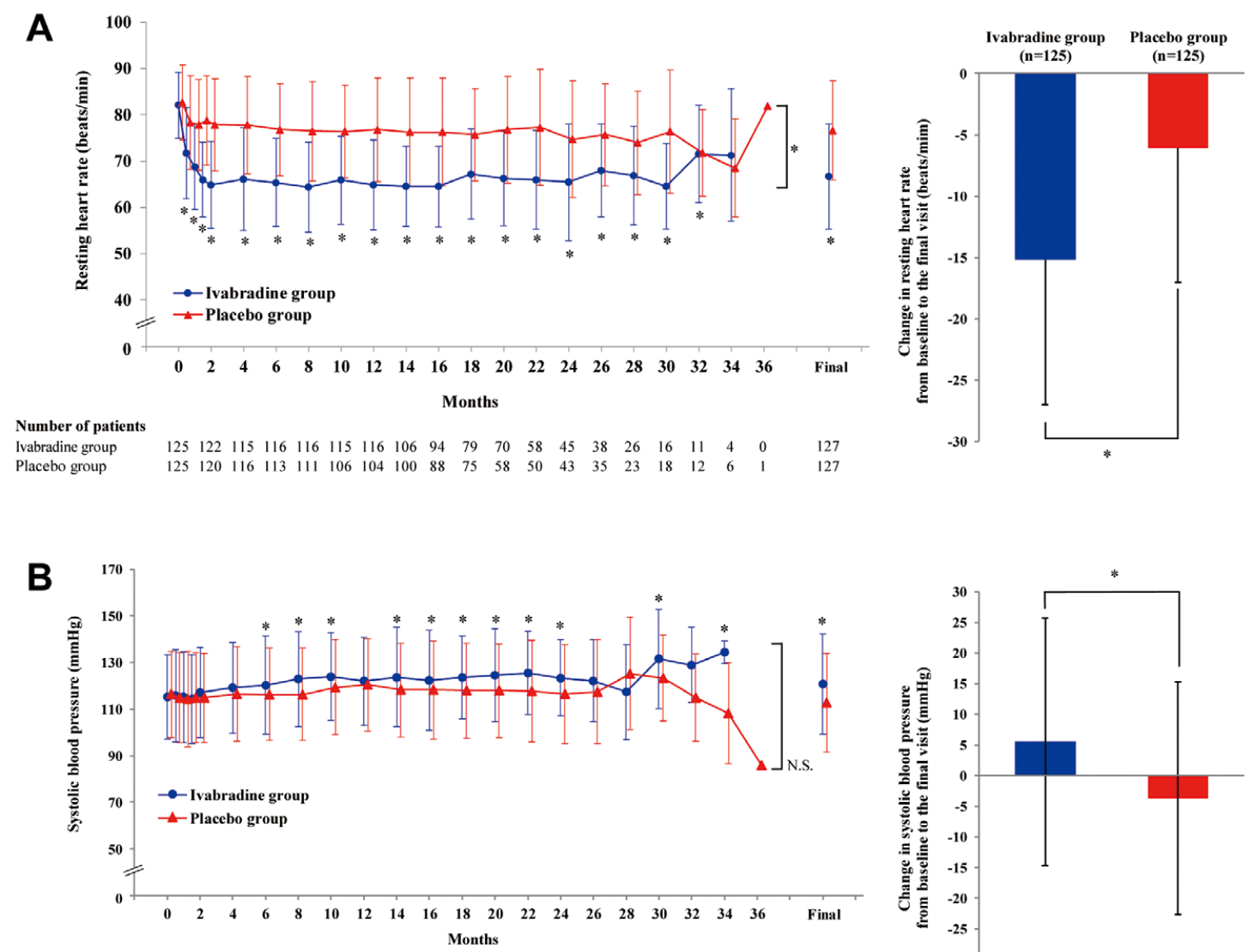

Number of patients Ivabradine group Placebo group

$\begin{array}{lllllllllllllllllllll}127 & 124 & 122 & 120 & 121 & 119 & 118 & 111 & 100 & 87 & 72 & 59 & 46 & 39 & 27 & 17 & 11 & 4 & 0 & 127\end{array}$ $\begin{array}{llllllllllllllllllll}127 & 123 & 119 & 115 & 114 & 110 & 106 & 102 & 91 & 79 & 63 & 54 & 46 & 37 & 25 & 18 & 13 & 6 & 1 & 127\end{array}$
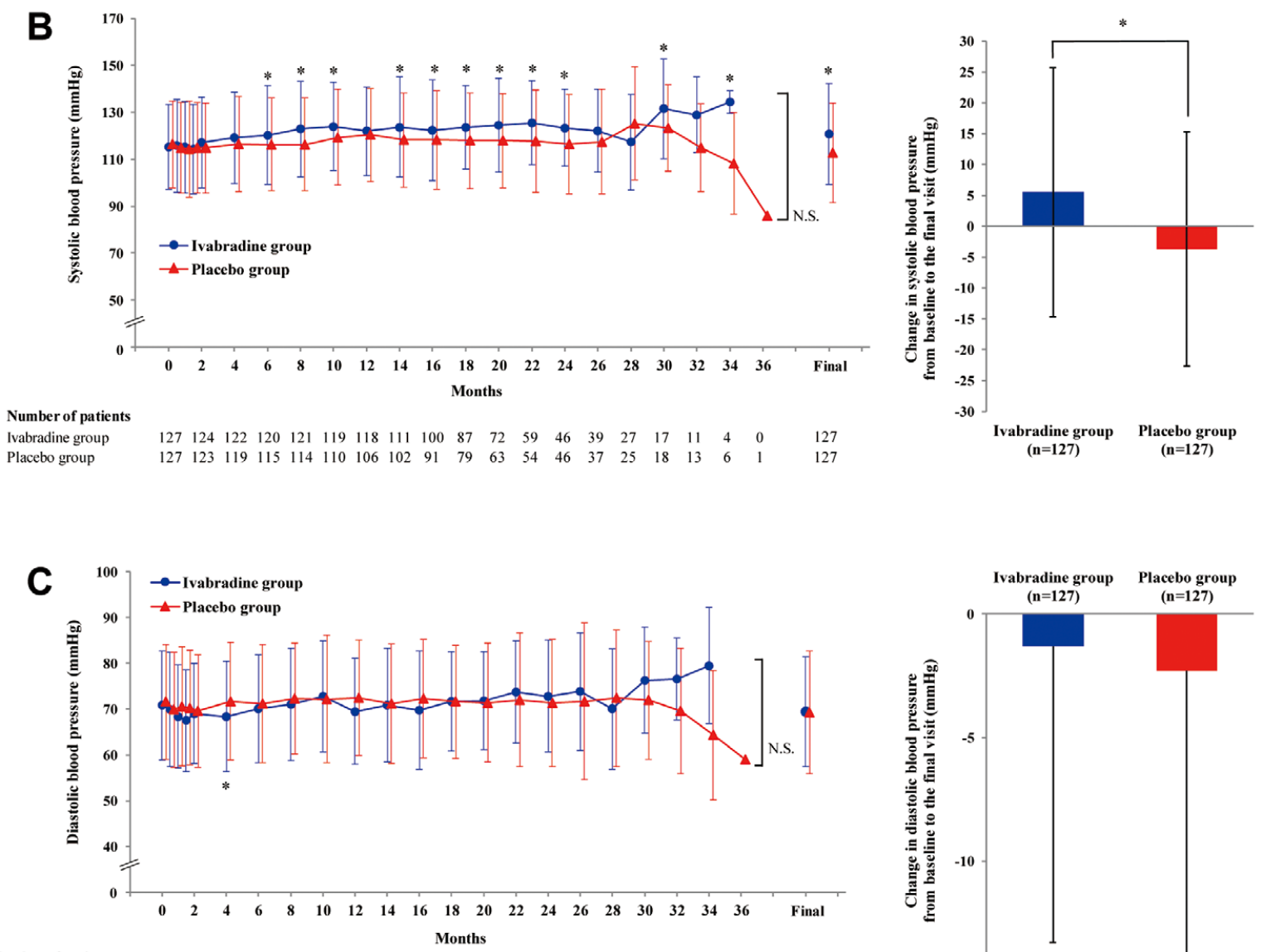

$\begin{array}{lllllllllllllllllllllll}\begin{array}{l}\text { Number of patients } \\ \text { Ivabradine group }\end{array} & 127 & 124 & 122 & 120 & 121 & 119 & 118 & 111 & 100 & 87 & 72 & 59 & 46 & 39 & 27 & 17 & 11 & 4 & 0 & 127\end{array}$

$\begin{array}{lllllllllllllllllllll}\text { Ivabradine group } & 127 & 124 & 122 & 120 & 121 & 119 & 118 & 111 & 100 & 87 & 72 & 59 & 46 & 39 & 27 & 17 & 11 & 4 & 0 & 127 \\ \text { Placebo group } & 127 & 123 & 119 & 115 & 114 & 110 & 106 & 102 & 91 & 79 & 63 & 54 & 46 & 37 & 25 & 18 & 13 & 6 & 1 & 127\end{array}$

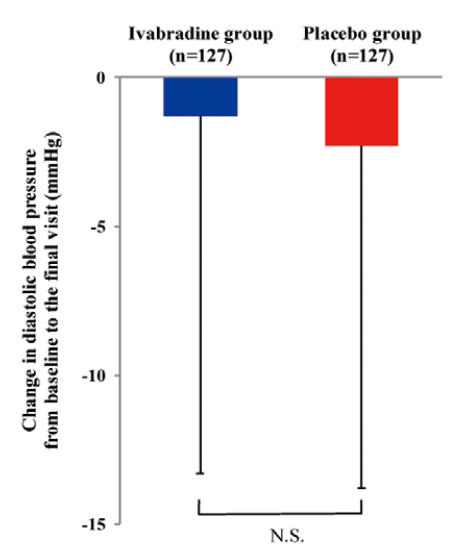

Figure 2. Time-dependent changes in (A) resting heart rate, (B) systolic blood pressure, and (C) diastolic blood pressure during the treatment. Data are shown as mean \pm SD. N.S., $P \geq 0.05$ vs. the placebo group at each time point or in the mean change from baseline. ${ }^{*}<<0.05$ vs. the placebo group at each time point or in the mean change from baseline.

$7.5 \mathrm{mg}$ BID, $20(15.7 \%)$ patients were on $5 \mathrm{mg}$ BID, and 7 $(5.5 \%)$ patients were on $2.5 \mathrm{mg}$ BID. A total of $11(8.7 \%)$ patients in the ivabradine and $20(15.7 \%)$ patients in the placebo group discontinued the study drug treatment. The median duration of follow-up was 582 and 589 days in the ivabradine and placebo groups, respectively ( $\mathrm{P}=0.9091)$.

\section{$H R$ and $B P$}

Resting HR was significantly reduced in the ivabradine group compared with the placebo group $(\mathrm{P}<0.0001)$ 


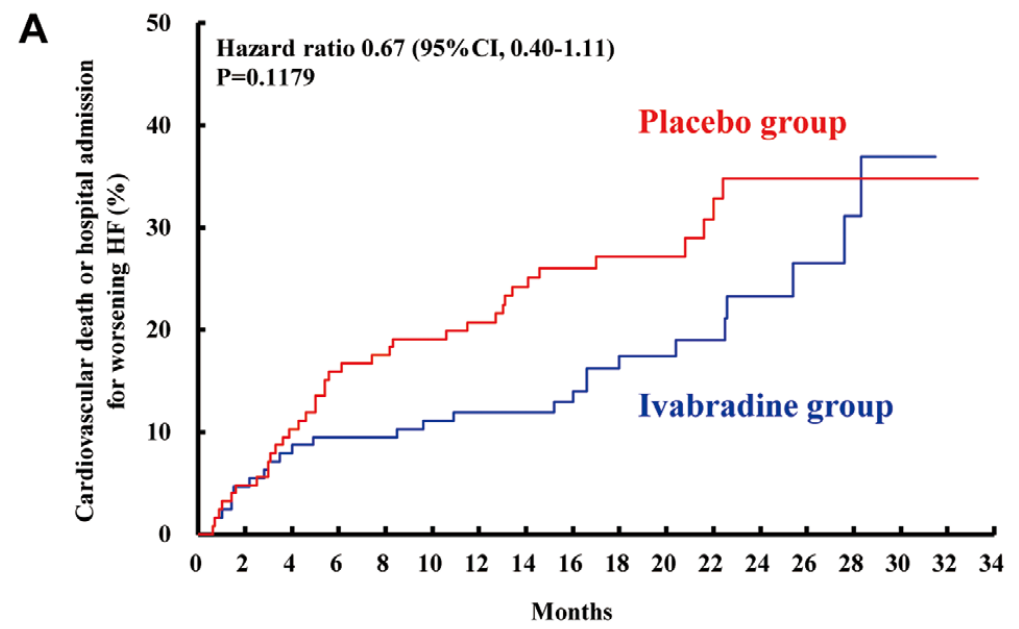

\section{Number at risk}

$\begin{array}{llllllllllllllllllll}\text { Ivabradine group } & 127 & 120 & 116 & 114 & 114 & 112 & 109 & 95 & 80 & 68 & 55 & 42 & 31 & 20 & 13 & 5 & 0 & 0\end{array}$

$\begin{array}{lllllllllllllllllllllll}\text { Placebo group } & 127 & 120 & 113 & 105 & 103 & 101 & 97 & 84 & 68 & 53 & 45 & 34 & 25 & 20 & 15 & 8 & 2 & 0\end{array}$

\section{B}

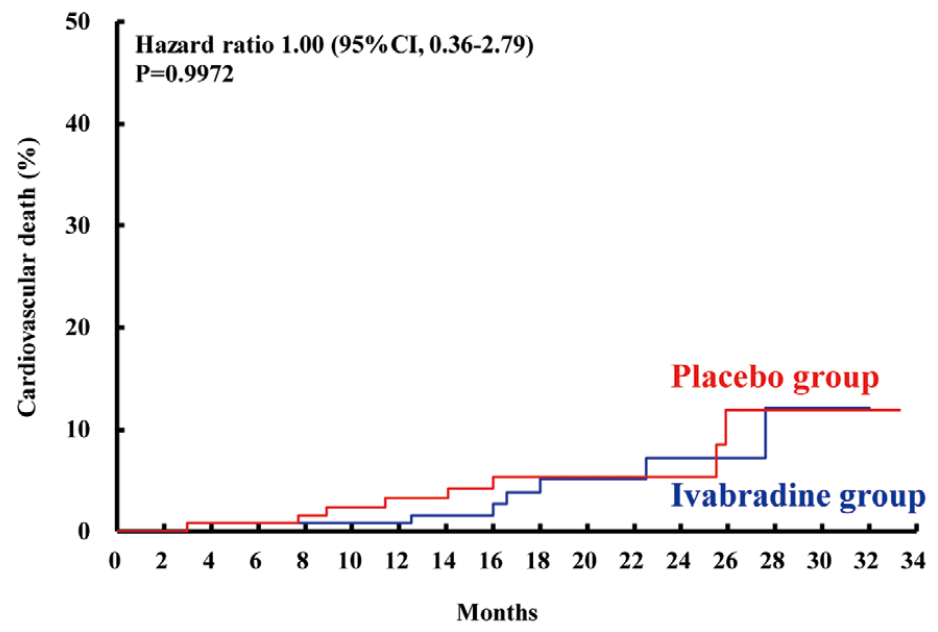

Number at risk

$\begin{array}{llllllllllllllllllll}\text { Ivabradine group } & 127 & 126 & 124 & 123 & 123 & 122 & 120 & 105 & 91 & 74 & 60 & 48 & 38 & 25 & 16 & 7 & 0 & 0\end{array}$

$\begin{array}{lllllllllllllllllll}\text { Placebo group } & 127 & 126 & 124 & 122 & 120 & 119 & 114 & 105 & 88 & 72 & 61 & 47 & 37 & 26 & 18 & 9 & 2 & 0\end{array}$

C

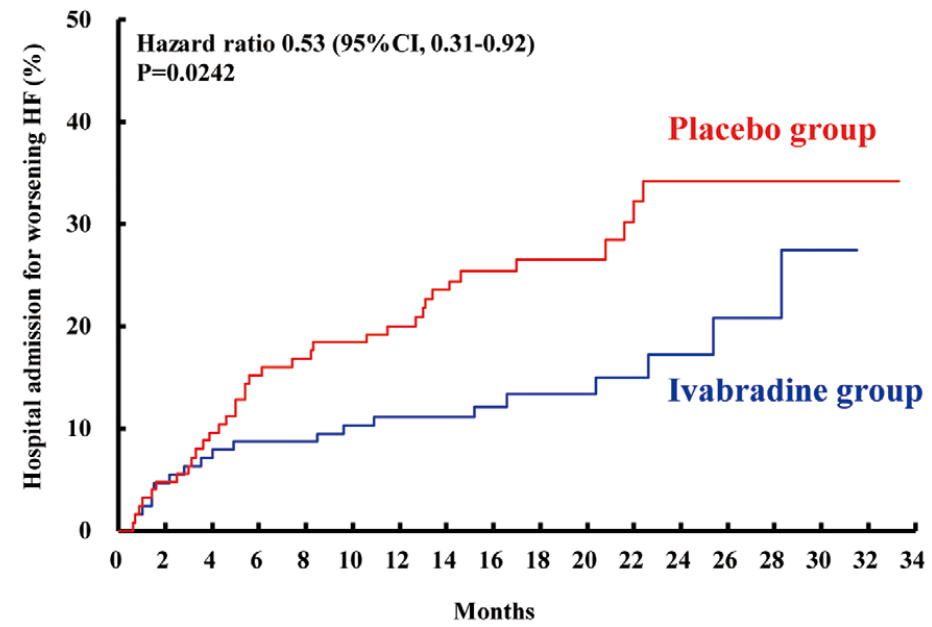

Number at risk

$\begin{array}{lllllllllllllllllll}\text { Ivabradine group } & 127 & 120 & 116 & 114 & 114 & 112 & 109 & 95 & 80 & 68 & 55 & 42 & 31 & 20 & 13 & 5 & 0 & 0\end{array}$

Placebo group $\begin{array}{llllllllllllllllll}127 & 120 & 113 & 105 & 103 & 101 & 97 & 84 & 68 & 53 & 45 & 34 & 25 & 20 & 15 & 8 & 2 & 0\end{array}$

Figure 3. Kaplan-Meier cumulative event curves for $(\mathbf{A})$ the primary composite endpoint of cardiovascular death or hospital admission for worsening heart failure, (B) cardiovascular death, and (C) hospital admission for worsening heart failure. Censoring data are not displayed. $\mathrm{Cl}$, confidence interval. 


\begin{tabular}{|c|c|c|c|c|}
\hline Efficacy endpoints & $\begin{array}{l}\text { Ivabradine group } \\
\qquad(\mathrm{n}=127)\end{array}$ & $\begin{array}{l}\text { Placebo group } \\
\quad(n=127)\end{array}$ & $\begin{array}{l}\text { Hazard ratio } \\
\quad(95 \% \mathrm{Cl})\end{array}$ & $\mathbf{P}$ value ${ }^{\dagger}$ \\
\hline \multicolumn{5}{|l|}{ Primary composite endpoint } \\
\hline $\begin{array}{l}\text { Cardiovascular death or hospital admission for } \\
\text { worsening HF }\end{array}$ & $26(20.5)$ & $37(29.1)$ & $0.67(0.40-1.11)$ & 0.1179 \\
\hline \multicolumn{5}{|l|}{ Secondary endpoints } \\
\hline All-cause death & $9(7.1)$ & $9(7.1)$ & $1.15(0.45-2.94)$ & 0.7669 \\
\hline Cardiovascular death & $7(5.5)$ & $8(6.3)$ & $1.00(0.36-2.79)$ & 0.9972 \\
\hline HF death & $1(0.8)$ & $6(4.7)$ & $0.20(0.02-1.70)$ & 0.1405 \\
\hline Hospital admission for all causes & $55(43.3)$ & $63(49.6)$ & $0.85(0.59-1.22)$ & 0.3649 \\
\hline Hospital admission for worsening HF & $20(15.7)$ & $36(28.3)$ & $0.53(0.31-0.92)$ & 0.0242 \\
\hline Hospital admission for cardiovascular causes & $36(28.3)$ & $48(37.8)$ & $0.73(0.47-1.12)$ & 0.1475 \\
\hline $\begin{array}{l}\text { Cardiovascular death, hospital admission for worsening } \\
\text { HF, or hospital admission for non-fatal MI }\end{array}$ & $26(20.5)$ & $37(29.1)$ & $0.67(0.40-1.11)$ & 0.1179 \\
\hline
\end{tabular}

Data are number of events (\%). ${ }^{\dagger}$ Cox proportional hazards analysis with baseline resting HR and percentage of the target $\beta$-blocker dose as covariates. $\mathrm{Cl}$, confidence interval. Other abbreviations as in Table 1.

(Figure 2A). Respective mean resting HR for the ivabradine and placebo groups was $82.1 \pm 7.2$ and $82.7 \pm 8.1$ at baseline, $66.0 \pm 8.1$ and $78.8 \pm 9.6$ at 6 weeks, $64.6 \pm 8.6$ and $76.3 \pm 11.7$ at 56 weeks, and $66.7 \pm 11.4$ and $76.6 \pm 10.7$ beats $/ \mathrm{min}$ at the final visit. Mean reduction in resting HR from baseline was significantly greater in the ivabradine group at $6(-15.9 \pm 8.4$ vs. $-4.0 \pm 9.0$ with a mean difference of $-11.9 \pm 1.1$ beats $/ \mathrm{min}$, $\mathrm{P}<0.0001), 56$ weeks $(-17.3 \pm 10.1$ vs. $-6.7 \pm 10.4$ with a mean difference of $-10.5 \pm 1.4$ beats $/ \mathrm{min}, \mathrm{P}<0.0001)$, and the final visit $(-15.2 \pm 11.8$ vs. $-6.1 \pm 10.9$ with a mean difference of $-9.2 \pm 1.4$ beats $/ \mathrm{min}, \mathrm{P}<0.0001)$.

SBP tended to increase $(\mathrm{P}=0.0802)$ and its mean change from baseline to the final visit significantly increased in the ivabradine group compared with the placebo group (5.5 \pm 20.2 vs. $-3.7 \pm 19.0 \mathrm{mmHg}, \mathrm{P}<0.0001)$ (Figure 2B). In contrast, DBP did not differ between the groups $(\mathrm{P}=0.5000)$ (Figure 2C).

\section{Efficacy}

The primary composite endpoint of cardiovascular death or hospital admission for worsening HF occurred at a lower rate in the ivabradine than in the placebo group (20.5 vs. $29.1 \%$ ). This difference did not reach statistical significance $(\mathrm{P}=0.1179)$; however, the hazard ratio was $<1$ (0.67; 95\% CI: 0.40-1.11) (Figure 3A; Table 2). The effects of ivabradine on the primary composite endpoint were consistent across both the prespecified and post-hoc subgroups (Figure 4). Importantly, these results were consistent across subgroups of $\%$ of target $\beta$-blocker dose $(0,>0-<25,25-<50,50-<100, \geq 100 \%)$. The rate of cardiovascular death was similar $(5.5 \%$ vs. $6.3 \%$; hazard ratio 1.00, 95\% CI: $0.36-2.79, \mathrm{P}=0.9972)$; however, that of hospital admission for worsening HF was significantly lower in the ivabradine group than in the placebo group ( $15.7 \%$ vs. $28.3 \%$; hazard ratio $0.53,95 \%$ CI: $0.31-0.92$, $\mathrm{P}=0.0242$ ) (Figure 3B,C; Table 2).

The distribution of NYHA functional class did not differ between the groups at 12, 24 months, or the final visit $(\mathrm{P}=0.8772,0.5219$ and 0.1914 , respectively) (Supplementary Figure 2A). However, the proportion of patients with improved, unchanged, and worsened NYHA functional class from baseline to the final visit differed between the ivabradine and the placebo groups $(\mathrm{P}=0.0316)$ (Supplementary Figure 2B), showing that more patients in the ivabradine group had improved or not changed NYHA functional class at the final visit.

LVEF significantly increased from $27.9 \pm 5.3 \%$ at baseline to $38.9 \pm 12.8 \%$ at the final visit in the ivabradine group compared with the placebo group, in which LVEF increased from $26.6 \pm 6.1 \%$ to $33.3 \pm 13.0 \%(\mathrm{P}=0.0004)$ (Figure 5A). Mean change in LVEF from baseline to the final visit was significantly greater in the ivabradine group $(11.1 \pm 10.7 \mathrm{vs}$. $6.6 \pm 11.9, \mathrm{P}<0.0001)$. LVESV index was significantly reduced in the ivabradine group compared with the placebo group ( $\mathrm{P}=0.0372$ ), but the LVEDV index did not differ between the groups $(\mathrm{P}=0.1312)$ (Figure 5B,C). However, the reduction from baseline to the final visit was significantly greater in the ivabradine group in both LVEDV index and LVESV index (Figure 5B,C).

There was no significant difference in the changes in plasma BNP and NT-pro BNP levels between the groups (Supplementary Figure 3).

\section{Relationship Among HR, LV Function, and Outcomes}

The primary composite endpoint of cardiovascular death or hospital admission for worsening HF was compared between subgroups according to the degree of median HR reduction at 6 weeks from baseline ( $>16$ beats $/ \mathrm{min}, \mathrm{n}=56 \mathrm{vs}$. $\leq 16$ beats/min, $n=64$ within the ivabradine group). It tended to be lower in patients with HR reduction $>16$ beats $/ \mathrm{min}$ compared with those $\leq 16$ beats/min (hazard ratio 0.69 , 95\%: CI 0.28-1.69, $\mathrm{P}=0.4161$ ), which, however, did not reach statistical significance (Supplementary Figure 4A). These results were mainly driven by the reduction in cardiovascular death (hazard ratio $0.07,95 \%$ CI: $0.00-1.22$, $\mathrm{P}=0.0677)$ rather than hospital admission for worsening HF (hazard ratio $1.09,95 \%$ CI: $0.41-2.93, \mathrm{P}=0.8647$ ) (Supplementary Figure 4B,C).

In the pooled ivabradine and placebo groups, the changes in LVEF and LVESV index were significantly greater in patients with median HR reduction $>11$ beats $/ \mathrm{min}$ $(9.5 \pm 10.0 \%$ vs. $6.6 \pm 9.7 \%, \mathrm{P}=0.0252$ for $\mathrm{LVEF}$ and $-15.7 \pm 21.6$ vs. $-8.1 \pm 27.0 \mathrm{~mL} / \mathrm{m}^{2}, \mathrm{P}=0.0187$ for LVESV index) (Supplementary Figure 5A,C). In addition, there was a significant linear correlation between the changes in HR and those in LVEF $(\mathrm{r}=-0.163, \mathrm{P}=0.0150)$ and LVESV index ( $r=0.151, P=0.0249)$. Similar to the pooled ivabradine and placebo groups, the change in LVESV index was 


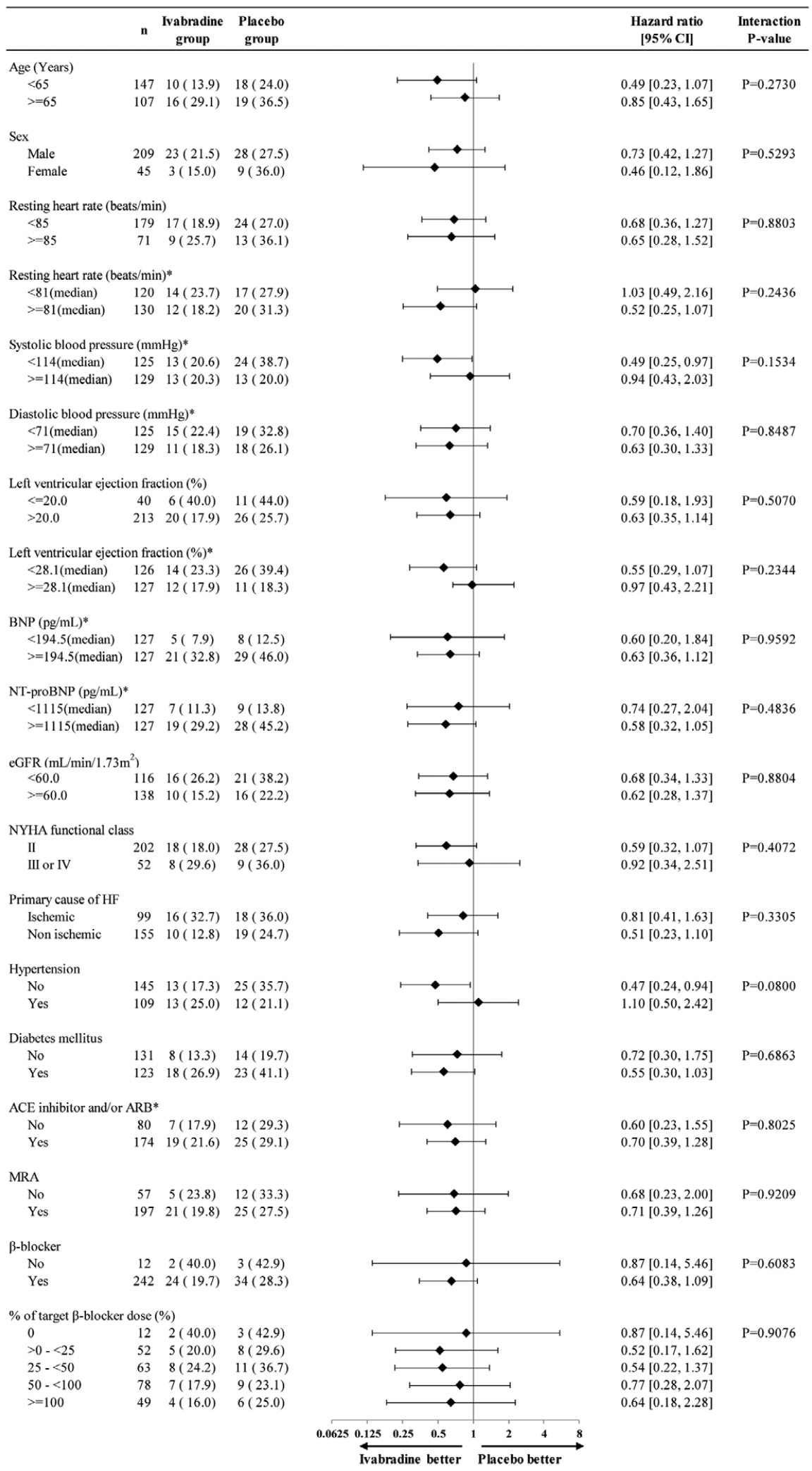

Figure 4. Hazard ratios for primary composite endpoint according to subgroups. Data are number (\%) of patients with first events. Target $\beta$-blocker dose: carvedilol $20 \mathrm{mg} /$ day and bisoprolol $5 \mathrm{mg} /$ day. *Post-hoc analysis. ACE, angiotensin-converting enzyme; ARB, angiotensin II receptor blocker; BNP, B-type natriuretic peptide; CI, confidence interval; eGFR, estimated glomerular filtration rate; HF, heart failure; MRA, mineralocorticoid receptor antagonist; NT-proBNP, N-terminal prohormone of BNP; NYHA, New York Heart Association. 
A

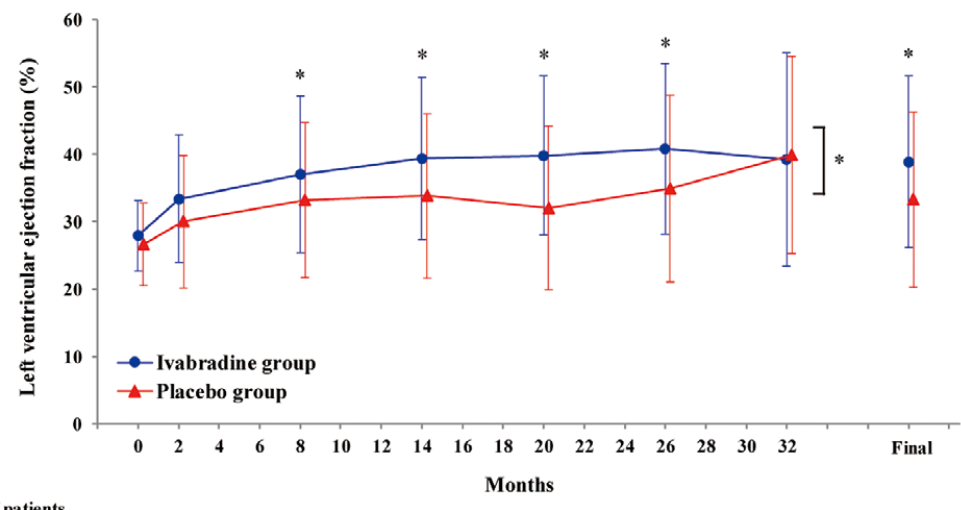

Number of patients

$\begin{array}{lllllllll}\text { Ivabradine group } & 127 & 122 & 120 & 111 & 72 & 38 & 11 & 126 \\ \text { Placebo group } & 126 & 123 & 113 & 101 & 63 & 37 & 13 & 127\end{array}$

113

$$
10103
$$

\section{B}

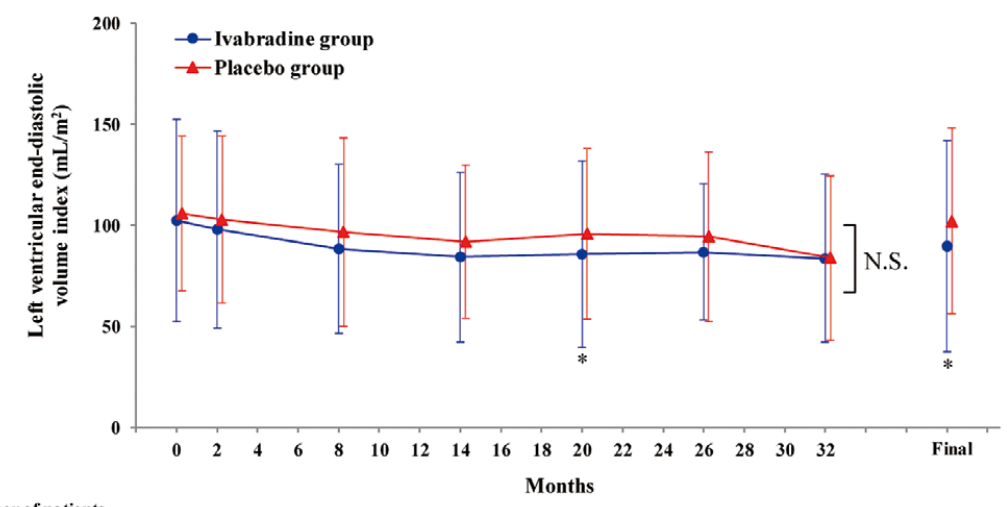

Number of patients

$\begin{array}{lllllllll}\text { Ivabradine group } & 127 & 122 & 120 & 111 & 72 & 37 & 11 & 126 \\ \text { Placebo group } & 126 & 123 & 113 & 101 & 63 & 37 & 13 & 127\end{array}$

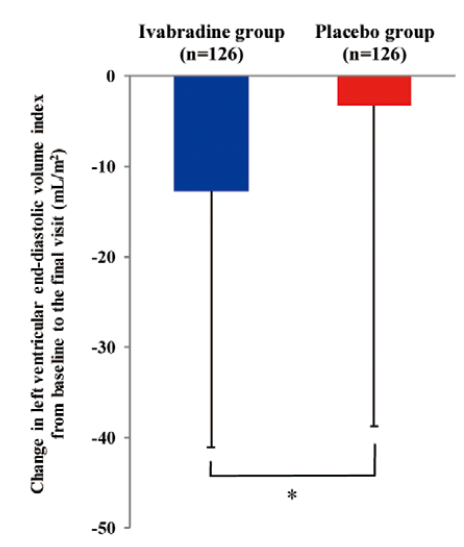

\section{C}

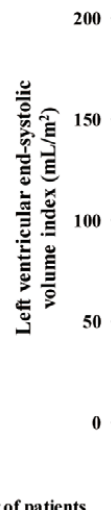

Number of patients

Ivabradine group

Placebo group

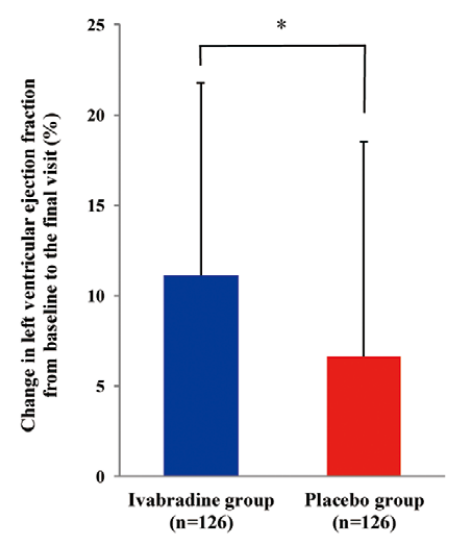

Figure 5. Changes in (A) left ventricular ejection fraction, (B) left ventricular end-diastolic volume index, and (C) left ventricular end-systolic volume index. Data are shown as mean \pm SD. N.S., $P \geq 0.05$ vs. the placebo group in the mean change from baseline. ${ }^{*} \mathrm{P}<0.05$ vs. the placebo group at each time point or in the mean change from baseline. 
Table 3. Incidence of AEs

\begin{tabular}{|c|c|c|c|c|c|c|}
\hline & \multicolumn{3}{|c|}{ AEs } & \multicolumn{3}{|c|}{ AEs leading to treatment discontinuation } \\
\hline & $\begin{array}{c}\text { Ivabradine } \\
\text { group }(n=127)\end{array}$ & $\begin{array}{l}\text { Placebo group } \\
(n=127)\end{array}$ & P value ${ }^{\star}$ & $\begin{array}{c}\text { Ivabradine } \\
\text { group }(n=127)\end{array}$ & $\begin{array}{l}\text { Placebo group } \\
(n=127)\end{array}$ & P value* \\
\hline All & $119(93.7)$ & $116(91.3)$ & 0.6344 & $11(8.7)$ & $10(7.9)$ & 1.0000 \\
\hline $\mathrm{HF}^{\star *}$ & $31(24.4)$ & $49(38.6)$ & 0.0214 & $4(3.1)$ & $6(4.7)$ & 0.7489 \\
\hline Phosphenes & $8(6.3)$ & $4(3.1)$ & 0.3760 & 0 & 0 & - \\
\hline Atrial fibrillation & $3(2.4)$ & $7(5.5)$ & 0.3339 & 0 & 0 & - \\
\hline Asymptomatic bradycardia & $1(0.8)$ & $1(0.8)$ & 1.0000 & 0 & 0 & - \\
\hline
\end{tabular}

Data are $n(\%)$. *Fisher's exact test. ${ }^{* *} \mathrm{HF}$, acute HF, chronic HF, and congestive HF were merged into HF. AE, adverse event; HF, heart failure.

significantly greater in patients with median $\mathrm{HR}$ reduction $>16$ beats/min also in the ivabradine group $(-19.9 \pm 20.0 \mathrm{vs}$. $-11.3 \pm 19.3 \mathrm{~mL} / \mathrm{m}^{2}, \mathrm{P}=0.0446$ ) (Supplementary Figure 5F).

To explore the effect of echocardiographic changes on clinical outcomes, the patients in the ivabradine group were divided according to median change in LVEF at 8 months $(\geq 7.9 \%, n=60$ vs. $<7.9 \%, n=60)$. The incidence of the primary composite endpoint of cardiovascular death and hospital admission for worsening HF was significantly lower in patients with a greater increase in LVEF (hazard ratio $0.18,95 \% \mathrm{CI}$ : $0.06-0.55, \mathrm{P}=0.0025$ ) (Supplementary Figure 6A). Similar results were also obtained in LVEDV index (hazard ratio $0.24,95 \% \mathrm{CI}$ : $0.08-0.66, \mathrm{P}=0.0057$ ) and LVESV index (hazard ratio $0.12,95 \% \mathrm{CI}$ : $0.03-0.41$, $\mathrm{P}=0.0007$ ) (Supplementary Figure 6B,C).

\section{Safety}

The incidence of AEs did not differ between the groups (93.7\% vs. $91.3 \%, \mathrm{P}=0.6344)$ and that of AEs leading to treatment discontinuation was also similar between the groups $(8.7 \%$ vs. $7.9 \%, \mathrm{P}=1.000)$ (Table 3). The most common AE was HF, which occurred less in the ivabradine group $(24.4 \%$ vs. $38.6 \%, P=0.0214)$, consistent with the efficacy results (Figure 2; Table 2). Phosphenes were observed in 8 patients $(6.3 \%)$ in the ivabradine group and in $4(3.1 \%)$ in the placebo group $(\mathrm{P}=0.3760)$. They were mild and did not need treatment discontinuation in either group. Incidence of atrial fibrillation tended to be lower in the ivabradine group (2.4 vs. 5.5\%), but did not reach statistical significance $(\mathrm{P}=0.3339)$. In each group, 1 case of asymptomatic bradycardia $(0.8 \%)$ was reported. No cases of symptomatic bradycardia were reported in either group.

There were no clinically significant changes in vital signs, laboratory parameters, or 12-lead ECG including QTc interval (data not shown).

\section{Discussion}

The J-SHIFT study demonstrated that ivabradine improved the primary composite endpoint of cardiovascular death or hospital admission for worsening HF in Japanese patients with NYHA functional class II-IV, LVEF $\leq 35 \%$, and resting $\mathrm{HR} \geq 75$ beats/min in sinus rhythm under optimal medical therapy with a hazard ratio of 0.67 (95\% CI: $0.40-1.11)$, confirming similar efficacy with the SHIFT study ${ }^{3}$ results (Figure 3; Table 2).

The effects of ivabradine on the primary composite endpoint in the J-SHIFT study were mainly from a reduction in hospital admission for worsening HF (hazard ratio 0.53) rather than cardiovascular death (hazard ratio 1.00)
(Figure 3; Table 2), consistent with the SHIFT study (hazard ratio: 0.74 for hospital admission for worsening $\mathrm{HF}$ and 0.91 for cardiovascular death). ${ }^{3}$ In addition, ivabradine reduced most of the cardiovascular endpoints, including HF death, hospital admission for all causes, cardiovascular causes, and worsening HF, and the secondary composite endpoint (Table 2). These results were also similar to those observed in the SHIFT study. ${ }^{3}$ Overall, the J-SHIFT study confirmed that ivabradine could provide similar improvements in clinical outcomes in Japanese HFrEF patients also, as observed in the SHIFT study.

The baseline characteritics of the studied patients were similar between the J-SHIFT and SHIFT studies except for the primary cause of HF and NYHA distribution (Supplementary Table 2). NYHA functional class was lower and non-ischemic cause was higher in Japanese patients, in line with previous clinical trials and registries. ${ }^{4,11}$ Despite these differences between the J-SHIFT and SHIFT studies, prespecified subgroup analyses in the SHIFT and J-SHIFT studies showed that neither factor influenced the effects of ivabradine on the primary composite endpoint. ${ }^{3}$

The use of ACE inhibitor and/or ARB was relatively low $(70 \%)$ in the J-SHIFT study (Table 1). Although the reasons for this low use of ACE inhibitor and/or ARB were not clear because the information was not available, the effects of ivabradine on the primary composite endpoint were consistent across subgroups with and without ACE inhibitor and/or ARB use (test for interaction $\mathrm{P}=0.8025$ ) (Figure 4). Beta-blockers were used in $95 \%$ of patients, but only $20 \%$ of patients were on the target dose (Table 1). The percentage distribution of doses of $\beta$-blockers in the J-SHIFT study was similar to that reported in the SHIFT study (Supplementary Table 2). The effects of ivabradine on the primary composite endpoint were consistent across subgroups with different doses of $\beta$-blockers (test for interaction $\mathrm{P}=0.9076$ ) (Figure 4). Moreover, mean daily doses of carvedilol of $9.8 \mathrm{mg}$ and bisoprolol of $3.1 \mathrm{mg}$ in the J-SHIFT study were comparable to those in clinical studies in Japan. ${ }^{12,13}$

Ivabradine reduced the resting HR by 15 beats/min from the baseline value of 82 beats/min and the reduced HR was well maintained throughout the course of the treatment period (Figure 2A). This reduction was consistent with the 15 beats/min reported in the SHIFT study. ${ }^{3}$ It was consistent also in subgroups, including the primary cause of $\mathrm{HF}$, baseline HR, baseline LVEF, and $\beta$-blocker dose (data not shown).

Another important finding of the J-SHIFT study was that ivabradine reversed LV remodeling and improved LVEF (Figure 5). Treatment with ivabradine was associated 
with a significant reduction in the LVESV index by $16.3 \mathrm{~mL} / \mathrm{m}^{2}$ and a significant increase in LVEF by $11.1 \%$. These results were in line with the decrease in LVESV index $\left(7.0 \mathrm{~mL} / \mathrm{m}^{2}\right)$ and the increase in LVEF $(2.4 \%)$ reported from the SHIFT echocardiography substudy. ${ }^{14}$ However, the extent of these changes was greater in the J-SHIFT study than in the SHIFT substudy.

The primary composite endpoint tended to be lower in patients with greater HR reduction (Supplementary Figure 4). In addition, there was a significant relationship between the changes in HR and those in LVEF (Supplementary Figure 5). The incidence of the primary composite endpoint was significantly lower in patients with a greater increase in LVEF (Supplementary Figure 6). The present study suggested that the LV functional and morphological changes induced by ivabradine might have relationships with $\mathrm{HR}$ reduction and prognosis. These positive effects of ivabradine on $\mathrm{LV}$ remodeling and prognosis were consistent with previous substudies of the SHIFT study. ${ }^{\mathbf{8 , 1 4}}$

The changes in the plasma BNP/NT-proBNP levels were not associated with echocardiographic LV functional changes in the J-SHIFT study. There are several explanations for the lack of an effect of ivabradine on BNP/NTproBNP in this study. First, a great variability in BNP/ NT-proBNP levels at baseline might make the comparison between the groups inconclusive, especially when the number of studied patients was as small as in this study. Second, the correlation between BNP/NT-proBNP and LVEF has been reported to be relatively weak. ${ }^{15}$ Third, the association between LV remodeling and natriuretic peptides has been reported to be unclear under treatment with $\beta$-blocker, in contract to that with ACE inhibitor. ${ }^{16}$ In fact, similar to our findings, the echocardiographic substudy of the BEAUTIFUL study in patients with coronary artery disease and LV dysfunction also reported that ivabradine did not have significant effects on NT-proBNP levels. ${ }^{17}$

Ivabradine was well tolerated by Japanese patients (Table 3). In the SHIFT study, visual side effects such as phosphenes, which are related to HCN inhibition in retina, ${ }^{18}$ symptomatic or asymptomatic bradycardia, and atrial fibrillation occurred more frequently in the ivabradine group compared with the placebo group. ${ }^{3}$ In the J-SHIFT study, the incidences of these AEs were comparable between the groups (Table 3). Notably, asymptomatic bradycardia occurred in 1 patient $(0.8 \%)$ in the ivabradine group, but this patient did not need to discontinue treatment, which is especially important considering that $95 \%$ of patients had $\beta$-blocker therapy. Mild phosphenes were observed in 8 patients $(6.3 \%)$ in the ivabradine group and this incidence was lower than that reported from the Japanese phase II trial $(9.5 \%)$, but was higher than in the SHIFT study $(3 \%)$. None of the patients discontinued treatment.

\section{Study Limitations}

There are several potential limitations to be acknowledged. First, the sample size of the J-SHIFT study was too small to evaluate clinical events with statistical significance. However, the sample size was considered suitable for evaluating the consistency of efficacy by ivabradine with that in the SHIFT study. Second, the J-SHIFT study excluded patients with persistent atrial fibrillation or flutter and the results can only be applied to patients with resting $\mathrm{HR} \geq 75$ beats/min and sinus rhythm. Third, the background medical treatment for HFrEF in the J-SHIFT study, espe- cially for ACE inhibitor or ARB and $\beta$-blocker, was not sufficient based on the Japanese guideline recommendations. ${ }^{6,7}$ Therefore, it is unclear whether the efficacy of ivabradine would be similar if more patients were treated by ACE inhibitor or ARB and on the target dose of $\beta$-blocker. However, the subgroup analysis of the J-SHIFT study demonstrated that the efficacy of ivabradine was consistent irrespective of the background treatments, as in the SHIFT study (Figure 4).

In conclusion, ivabradine had efficacy and safety in Japanese patients with HFrEF, consistent with the SHIFT study.

\section{Acknowledgments}

We thank all the patients, investigators, staff who participated in this study, and Professor Takuhiro Yamaguchi of Tohoku University for providing statistical advice.

\section{Disclosures}

This trial was designed and performed by the sponsor, Ono Pharmaceutical Co., Ltd. The data were collected and analyzed, and the first draft manuscript was written by the sponsor. It was fully reviewed and revised by the authors.

H.T. received remuneration from Otsuka, Takeda, Mitsubishi Tanabe, Daiichi Sankyo, Boehringer Ingelheim Japan, Bayer, and Pfizer; research funding from Boehringer Ingelheim Japan and Mitsubishi Tanabe; and scholarship funds from MSD, Daiichi Sankyo, Mitsubishi Tanabe, Teijin Pharma, and Boehringer Ingelheim Japan. A.Y. received remuneration from Daiichi Sankyo Pharmaceutical Company and Mitsubishi Tanabe Pharmaceutical Company. H.S. received remuneration from Daiichi Sankyo Co. Ltd. and Bayer Yakuhin, Ltd.; research funding from Bayer Yakuhin, Ltd.; scholarship funds from Astellas Pharma Inc., MSD K.K., Otsuka Pharmaceutical Co., Ltd., Shionogi \& Co., Ltd., Mitsubishi Tanabe Pharma Co., Daiichi Sankyo Co. Ltd., Sumitomo Dainippon Pharma Co., Ltd., Teijin Pharma Ltd., and Nippon Shinyaku Co., Ltd.; and is affiliated with an endowed department sponsored by Abbott Vascular Japan Co., Ltd., Abbott Medical Japan Co., Ltd., Tesco Co., Ltd., Terumo Co., Ltd., Nihon Kohden Co., Ltd., Medtronic Japan Co., Ltd., Japan Lifeline Co., Ltd., Astellas Pharma Inc., AstraZeneca K.K., Japan Heart Foundation, Kowa Pharmaceutical Co., Ltd., Mochida Pharmaceutical Co., Ltd., Nippon Shinyaku Co., Ltd., Nippon Boehringer Ingelheim Co., Ltd., Otsuka Pharmaceutical Co., Ltd., Ono Pharmaceutical Co., Ltd., Takeda Pharmaceutical Co., Ltd., and Zeon Medical Inc. Y. Saito received remuneration from Mitsubishi Tanabe Pharma Corporation, Otsuka Pharmaceutical Co., Ltd., and Novartis Pharma K.K.; research funding from Novartis Pharma K.K., Amgen Astellas BioPharma K.K., and Terumo Corporation; scholarship funds from Astellas Pharma Inc., Otsuka Pharmaceutical Co., Ltd., Takeda Pharmaceutical Co., Ltd., Teijin Pharma Ltd., Bayer Holding Ltd., Daiichi Sankyo Co., Ltd., and Mitsubishi Tanabe Pharma Corporation; and is affiliated with an endowed department sponsored by MSD K.K. N.H. received remuneration from Nippon Boehringer Ingelheim Co., Ltd., Bristol-Myers Squibb, and Bayer Yakuhin, Ltd.; and scholarship funds from Aegerion Pharmaceuticals Inc., Otsuka Pharmaceutical Co., Ltd., Astellas Pharma Inc., Bayer Yakuhin, Ltd., Nippon Boehringer Ingelheim Co., Ltd., Daiichi Sankyo Co., Ltd., and Takeda Pharmaceutical Co., Ltd. H.I. received remuneration from Daiichi Sankyo, Mitsubishi Tanabe, Otsuka, Bayer, and Boehringer Ingelheim; scholarship funds from Daiichi Sankyo, Mitsubishi Tanabe, Otsuka, Bayer, Boehringer Ingelheim, Takeda, Mochida, and Ono Pharma Co.; and is affiliated with an endowed department sponsored by Medtronic Japan. M.Y. received remuneration and scholarship funds from Ono Pharmaceutical Co. Ltd. K.Y. received remuneration from Otsuka Pharmaceutical Co. Ltd., Takeda Pharmaceutical Co. Ltd., Ono Pharmaceutical Co. Ltd., Daiichi Sankyo Co. Ltd., and Mitsubishi Tanabe Pharma Co. Ltd; and scholarship funds from St. Jude Medical Japan Co. Ltd., Otsuka Pharmaceutical Co. Ltd., Daiichi Sankyo Co. Ltd., Johnson \& Johnson, Biotronik Japan Inc., Japan Lifeline Co. Ltd., Teijin Pharma Ltd., Mitsubishi Tanabe Pharma Co. Ltd., Fukuda Denshi, Takeda Pharmaceutical Co. Ltd., Nihon Kohden Co. Ltd. Novartis, Pfizer Inc, and Boston Scientific Co. Ltd. Y. Sakata received remuneration from Otsuka Pharmaceutical and Daiichi Sankyo, and scholarship funds from Ono Pharmaceutical. 
T.T. and Y. Kawasaki are employees of Ono Pharmaceutical. The remaining authors have nothing to disclose.

\section{References}

1. Pocock SJ, Wang D, Pfeffer MA, Yusuf S, McMurray JJ, Swedberg KB, et al. Predictors of mortality and morbidity in patients with chronic heart failure. Eur Heart J 2006; 27: 65-75.

2. Ide T, Ohtani K, Higo T, Tanaka M, Kawasaki Y, Tsutsui $\mathrm{H}$ Ivabradine for the treatment of cardiovascular diseases. Circ $J$ 2019; 83: $252-260$.

3. Swedberg K, Komajda M, Böhm M, Borer JS, Ford I, DubostBrama A, et al. Ivabradine and outcomes in chronic heart failure (SHIFT): A randomised placebo-controlled study. Lancet 2010; 11: $875-885$.

4. Tsutsui H, Momomura S, Yamashina A, Ogawa H, Shimokawa $\mathrm{H}$, Kihara $\mathrm{Y}$, et al. Heart rate control with If inhibitor, ivabradine, in Japanese patients with chronic heart failure: A randomized, double-blind, placebo-controlled phase II study. Circ J 2016; 80: 668-676.

5. Tsutsui H, Ito H, Kitakaze M, Komuro I, Murohara T, Izumi T, et al. Double-blind, randomized, placebo-controlled trial evaluating the efficacy and safety of eplerenone in Japanese patients with chronic heart failure (J-EMPHASIS-HF). Circ J 2017; 82: $148-158$.

6. Matsuzaki M, Ishii M, Izumi T, Ito H, Ito H, Ueda Y, et al. Guidelines for treatment of chronic heart failure (JCS 2010) (updated September 13, 2013). http://www.j-circ.or.jp/guideline/ pdf/JCS2010_matsuzaki_h.pdf (accessed December 1, 2018)

7. Tsutsui $\mathrm{H}$, Isobe $\mathbf{M}$, Ito $\mathrm{H}$, Ito $\mathrm{H}$, Ito $\mathrm{H}$, Okumura $\mathrm{K}$, et al. Guidelines for diagnosis and treatment of acute and chronic heart failure (JCS 2017/JHFS 2017). http://www.j-circ.or.jp/ guideline/pdf/JCS2017_tsutsui_h.pdf (accessed December 1, 2018).

8. Böhm M, Borer J, Ford I, Gonzalez-Juanatey JR, Komajda M, Lopez-Sendon J, et al. Heart rate at baseline influences the effect of ivabradine on cardiovascular outcomes in chronic heart failure: Analysis from the SHIFT study. Clin Res Cardiol 2013; 102: $11-22$.

9. World Medical Association. World Medical Association Declaration of Helsinki: Ethical principles for medical research involving human subjects. Bull World Health Organ 2001; 79: 373-374.
10. ICH Steering Committee. Guideline for good clinical practice E6 (R1). 1996. https://www.ich.org./fileadmin/Public_Web_Site/ ICH_Products/Guidelines/Efficacy/E6/E6_R1_Guideline.pdf (accessed December 1, 2018).

11. Shiba N, Shimokawa H. Prospective care of heart failure in Japan: Lessons from CHART studies. EPMA J 2011; 2: 425438.

12. Mori Y, Nishikawa Y, Kobayashi F, Hiramatsu K. Clinical status and outcome of Japanese heart failure patients with reduced or preserved ejection fraction treated with carvedilol. Int Heart J 2013; 54: 15-22.

13. Hori M, Nagai R, Izumi T, Matsuzaki M. Efficacy and safety of bisoprolol fumarate compared with carvedilol in Japanese patients with chronic heart failure: Results of the randomized, controlled, double-blind, Multistep Administration of bisoprolol IN Chronic Heart Failure II (MAIN-CHF II) study. Heart Vessels 2014; 29: 238-247.

14. Tardif JC, O`Meara E, Komajda M, Böhm M, Borer JS, Ford I, et al. Effects of selective heart rate reduction with ivabradine on left ventricular remodeling and function: Results from the SHIFT echocardiography substudy. Eur Heart J 2011; 32: $2507-$ 2515.

15. Troughton RW, Richards AM, Yandle TG, Frampton CM, Nicholls MG. The effects of medications on circulating levels of cardiac natriuretic peptides. Ann Med 2007; 39: 242-260.

16. Rosenberg J, Gustafsson F, Remme WJ, Riegger GA, Hildebrandt PR. Effect of beta-blockade and ACE inhibition on B-type natriuretic peptides in stable patients with systolic heart failure. Cardiovasc Drugs Ther 2008; 22: 305-311.

17. Ceconi C, Freedman SB, Tardif JC, Hildebrandt P, McDonagh $\mathrm{T}$, Gueret $\mathrm{P}$, et al. Effect of heart rate reduction by ivabradine on left ventricular remodeling in the echocardiographic substudy of BEAUTIFUL. Int J Cardiol 2011; 146: 408-414.

18. Cervetto L, Demontis GC, Gargini C. Cellular mechanisms underlying the pharmacological induction of phosphenes. $B r J$ Pharmacol 2007; 150: 383-390.

\section{Supplementary Files}

Please find supplementary file(s);

http://dx.doi.org/10.1253/circj.CJ-19-0227 